\title{
Michèle Maitron-Jodogne, Alain-Fournier et Yvonne de Quiévrecourt. Fecondité d'un renoncement
}

\section{Emanuele Kanceff}

\section{(2) OpenEdition}

1 Journals

\section{Edizione digitale}

URL: https://journals.openedition.org/studifrancesi/26786

DOI: 10.4000/studifrancesi.26786

ISSN: 2421-5856

\section{Editore}

Rosenberg \& Sellier

\section{Edizione cartacea}

Data di pubblicazione: 1 avril 2007

Paginazione: 121

ISSN: 0039-2944

\section{Notizia bibliografica digitale}

Emanuele Kanceff, «Michèle Maitron-Jodogne, Alain-Fournier et Yvonne de Quiévrecourt. Fecondité d’un renoncement», Studi Francesi [Online], 151 (LI | I) | 2007, online dal 30 novembre 2015, consultato il 23 novembre 2021. URL: http://journals.openedition.org/studifrancesi/26786 ; DOI: https://doi.org/ 10.4000/studifrancesi.26786

Questo documento è stato generato automaticamente il 23 novembre 2021.

\section{(c) $(1) \odot$}

Studi Francesi è distribuita con Licenza Creative Commons Attribuzione - Non commerciale - Non opere derivate 4.0 Internazionale. 


\title{
Michèle Maitron-Jodogne, Alain- Fournier et Yvonne de Quiévrecourt. Fecondité d'un renoncement
}

\author{
Emanuele Kanceff
}

\section{NOTIZIA}

AA. VV., MICHÈLE MAITRON-JODOGNE, Alain-Fournier et Yvonne de Quiévrecourt. Fecondité d'un renoncement, Bruxelles, P.I.E. Peter Lang, 2000, pp. 343.

1 Tra tanta letteratura critica gratuita, ecco un libro illuminante, di cui fa piacere parlare. Un libro scritto con amore, ma senza cedimenti e con penetrante acume.

2 La vicenda è nota e sull'incontro sconvolgente sono stati scritti fiumi di parole. Perché, allora, riprendere il discorso? Per la confusione che ancora esiste tra opera e biografia, prima di tutto, per il confine ancora incerto fra l'una e l'altra, sicché la vita dello scrittore è volentieri vista attraverso il filtro del romanzo. Per le zone d'ombra che persistono, nonostante tutto, nei due incontri con Yvonne de Quiévrecourt (e non Quièvrecourt come vorrebbero le regole grammaticali) nel 1905 e nel 1913 e che impediscono una esatta percezione delle differenze tra la storia amorosa reale e quella immaginaria dei personaggi del romanzo. Perché, poi, visti i rapporti strettissimi che esistono tra vissuto e scrittura per Fournier, è necessario che sia fatta la massima chiarezza sui fatti e sulle connessioni, approfondendo nello stesso tempo l'esame dei dati biografici e delle loro relazioni con l'opera letteraria. Per una ragione, infine, che l'autrice ha finemente intuito, che costituisce la parte più preziosa del suo lavoro e che così lei stessa definisce: «Très précocement et très profondément le jeune homme [Fournier] se veut écrivain, mais ce projet littéraire - indiscutable - est comme inclus dans un projet plus vaste, celui de se trouver lui-même, de trouver par dévoilements successifs un mode de vie qui lui soit propre et, tout à la fois, touche à l' essentiel. Dans cette perspective, le roman projeté répond moins peut-être, pour Fournier, au désir de 
témoigner d'une expérience dans un langage esthétiquement satisfaisant qu' à la nécessité de progresser en lui-même et de faire la lumière sur ses obscurités et contradictions intérieures. Rien n'est possible sans ce roman, et, dans cette mesure, il se présente souvent comme une fin, mais, en profondeur, le but poursuivi le dépasse et l' englobe et, cette fois, il a valeur de moyen».

3 Su questa base si sviluppa la fine e serrata analisi che Michèle Maitron mette in opera, $\mathrm{e}$ che saggiamente parte da una puntuale messa a punto dell'evoluzione del "regard critique" tra il "texte fondateur" costituito dall'«Alain-Fournier» di Jacques Rivière (articolo del 1923 curiosamente non citato nella Bibliografia) e la fine del mito sancita negli studi di fine Novecento. Essa prosegue poi per tappe essenziali, fra loro complementari e ineludibili, come la ricostruzione del tema basilare dell'infanzia e dell'adolescenza, l'incontro del maggio 1905 con Yvonne, il periodo che l'autrice individua come «travail du deuil» e come "prémices d'une évolution» (1905-1909), e poi quello della creazione letteraria (1909-1912) e della genesi del Grand Meaulnes. Del romanzo si analizzano gli aspetti fondanti in relazione alla biografia. Ma la conclusione del romanzo non significa conclusione del fascino di Yvonne. Nuove prove attendono Fournier, una nuova avventura spirituale in seguito alla rinuncia definitiva, nuove e pur brevi stagioni di scrittura prima della prematura scomparsa in battaglia il 22 settembre 1914. Sono l'oggetto dei capitoli conclusivi di questo bello studio, che si legge come un romanzo senza che venga mai meno la lucidità critica e che ha il meritodi restituirci tutta la freschezza e il fascino di una grande scrittura e di una avventura umana unica. 